\title{
Vasculitis and Anaphylactoid Shock Induced in Mice by Cell Wall Extract of the Fungus Candida metapsilosis
}

\author{
RUI TADA, DAISUKE YAMANAKA, NORIKO NAGI-MIURA, YOSHIYUKI ADACHI \\ and NAOHITO OHNO*

\begin{abstract}
Laboratory for Immunopharmacology of Microbial Products, School of Pharmacy,
\end{abstract} \\ Tokyo University of Pharmacy and Life Sciences, Tokyo, Japan
}

Submitted 1 October 2012, revised 17 January 2014, accepted 12 May 2014

\begin{abstract}
To investigate whether cell wall mannan from Candida metapsilosis induces vasculitis similar to that in Kawasaki syndrome and anaphylactoid shock in mice, we examined the pathogenic effects of $C$. metapsilosis cell wall extracts. Our results show that intraperitoneal injection of cell wall extracts induced severe coronary arteritis, and intravenous injection induced acute anaphylactoid shock similar to extracts from Candida albicans (C. albicans). Structural analysis of cell wall mannan from C. metapsilosis using NMR spectroscopy showed it to contain only $\alpha$-mannan, indicating that $\alpha$-mannan might be contributing to Candida pathogenicity by inducing coronary arteritis and acute shock.
\end{abstract}

Ke y word s: anaphylactoid shock; Candida metapsilosis; cell wall mannan; vasculitis

\section{Introduction}

Kawasaki syndrome (KS) is a systemic childhood vasculitis that can result in aneurysms in the coronary arteries (Burns 2009). Currently, the etiology of KS is largely unknown. However, many recent studies reported that KS might be triggered by a response to infectious agents, e.g., fungi, bacteria, and viruses (Akiyama and Yashiro 1993; Esper et al., 2005; Wang et al., 2005). Moreover, invasive Candida infection in neonates can cause mycetoma of the right atrium and candidal endocarditis (Levy et al., 2006). Pathogenic fungi, including Candida species, can induce septic shock, which is as great a clinical problem as bacterial septic shock.

Species of the yeast genus Candida, such as Candida albicans (C.albicans), are now one of the most common pathogenic microbes causing bloodstream infections in immunocompromised individuals, including those with human immunodeficiency virus infection. Recently, Candida metapsilosis has emerged as a cause of nosocomial infections, and is now considered an important pathogenic yeast (Bille et al., 2005; Krcmery and Barnes 2002; Jarvis 1995; Tay et al., 2009).
Candida cells are surrounded by a cell wall. Being external, it plays a crucial covering role, offering mechanical strength and protection from the hostile environment. Candida cell wall has a dynamic structure and is a complex mixture of different polysaccharides $(\sim 85 \%)$ and proteins $(\sim 15 \%)$. Cell wall polysaccharides are composed of $\beta$-glucan, chitin, and mannoprotein (Klis et al., 2001). The cell wall has been extensively studied for the following reasons: First, because the fungal cell wall is now considered a good candidate for the development of antifungal drugs, owing to its unique composition. Second, it has pivotal roles in virulence. Since the fungal cell wall is located at the outer surface, it is necessarily involved in adherence between host cells and fungal cells, a major virulence trait. Third, cell wall polysaccharides have a pathogen-specific structure, called pathogen-associated molecular patterns (PAMPs), that contributes to many pathogenic activities (Bourgeois etal., 2010; Arana et al., 2009; Nather and Munro 2008; Ruiz-Herrera et al., 2006; Poulain and Jouault 2004; Bowman and Free 2006). As mentioned previously, many recent studies showed that KS might be triggered by a response to an infectious agent. For the pathogenic yeast Candida albicans,

\footnotetext{
* Corresponding author: N. Ohno, Laboratory for Immunopharmacology of Microbial Products, School of Pharmacy, Tokyo University of Pharmacy and Life Sciences, 1432-1, Horinouchi, Hachioji, Tokyo 192-0392 Japan; phone: 81-426-76-5561; fax: 81-426-76-5570; e-mail: ohnonao@toyaku.ac.jp
} 
we previously reported that polysaccharide fractions obtained from the cell wall and from those secreted into culture media induced coronary arteritis similar to $\mathrm{KS}$ as well as acute anaphylactoid shock in mice (Ohno 2008; Miura et al., 2009; Tada et al., 2006; Nagi-Miura et al., 2006). In addition, we recently reported similar results that the polysaccharide fraction obtained from the culture supernatant of $C$. metapsilosis induces these symptoms (Tada et al., 2011), indicating that the pathogenic effects of the polysaccharide component are not specific to C. albicans.

In the course of our studies, we recently found a relationship between the structure of mannans from Candida species and the induction of several biological effects of the C.albicans water-soluble fraction (CAWS), including acute anaphylactoid shock, coronary arteritis, and complement activation. Specifically, a 1,2- $\beta$-mannosyl linkage within the mannan moiety of these fractions significantly reduced the biological effects described above (Tada et al., 2008; Shinohara et al., 2006). This result was also supported by investigations into the activity of cell wall mannan extracts of C. albicans, the structures of which change in response to changes in the culture conditions, such as medium and growth temperature (Okawa et al., 1996; Kobayashi et al., 1994; Koyama et al., 2009).

We hypothesize that cell wall polysaccharide fractions from C. metapsilosis could induce such an activity, because it is well known that the cell mannan of C. metapsilosis does not contain 1,2- $\beta$ linkages within its mannan moiety (Shibata et al., 1995). In the present study, we examined whether cell wall extracts prepared from C. metapsilosis can indeed induce those same pathogenic effects in mice as effectively as extracts from C. albicans. We prepared cell wall mannans from C. metapsilosis, assessed its pathogenic activities, such as induction of vasculitis and acute anaphylactoid shock, and analyzed the mannan structure.

\section{Experimental}

\section{Materials and Methods}

Animals and materials. Male ICR and DBA/2 mice (6 weeks old) were purchased from Japan SLC. The mice were housed in a specific pathogen free (SPF) environment. All animal experiments followed the guidelines for laboratory animal experiments in the Tokyo University of Pharmacy and Life Sciences (TUPLS), and each experimental protocol was approved by the committee on laboratory animal experiments at TUPLS. The completely synthetic C-limiting medium (Shepherd and Sullivan 1976) contained (per liter) the following: sucrose, $10 \mathrm{~g} ;\left(\mathrm{NH}_{4}\right)_{2} \mathrm{SO}_{4}, 2 \mathrm{~g} ; \mathrm{KH}_{2} \mathrm{PO}_{4}, 2 \mathrm{~g} ; \mathrm{CaCl}_{2} \cdot 2 \mathrm{H}_{2} \mathrm{O}$,
$0.05 \mathrm{~g} ; \mathrm{MgSO}_{4} \cdot 7 \mathrm{H}_{2} \mathrm{O}, 0.05 \mathrm{~g} ; \mathrm{ZnSO}_{4} \cdot 7 \mathrm{H}_{2} \mathrm{O}, 1 \mathrm{mg} ;$ $\mathrm{CuSO}_{4} \cdot 5 \mathrm{H}_{2} \mathrm{O}, 1 \mathrm{mg} ; \mathrm{FeSO}_{4} \cdot 7 \mathrm{H}_{2} \mathrm{O}, 0.01 \mathrm{~g}$; biotin, $25 \mu \mathrm{g}$; final $\mathrm{pH}, 5.2$.

Microbes and culture conditions. C. metapsilosis NBRC 0640 was obtained from the National Institute of Technology and Evaluation Biological Resource Center (NBRC). C. metapsilosis was grown as follows: $4 \mathrm{~L}$ of synthetic C-limiting medium was added to a fermentor and yeasts were cultured for 2 days at $27^{\circ} \mathrm{C}$ or $37^{\circ} \mathrm{C}$ with air supplied at a rate of $4 \mathrm{~L} / \mathrm{min}$. Following culturing, an equal volume of ethanol was added to kill the yeasts. Cells were then extensively washed with distilled water and acetone-dried. Acetone-dried cells were further delipidated with $\mathrm{CHCl}_{3}-\mathrm{MeOH}(2: 1, \mathrm{v} / \mathrm{v} ; 600 \mathrm{~mL})$ for $2 \mathrm{~h}$ under reflux. The residual cells were then washed with $\mathrm{EtOH}(600 \mathrm{~mL})$ for $2 \mathrm{~h}$ under reflux to remove low molecular weight organic compounds.

Preparation of cell wall extract (Tada et al., 2008). The washed cells $(20 \mathrm{~g})$ were suspended in $1 \mathrm{~L}$ of distilled water and then autoclaved for $4 \mathrm{~h}$ at $128^{\circ} \mathrm{C}$. This suspension was allowed to cool to room temperature (RT). After centrifugation, the supernatant was carefully collected. Residual sediment was re-extracted twice by the methods described above. The combined supernatants were concentrated at $40^{\circ} \mathrm{C}$ in vacuo to about $250 \mathrm{~mL}$. After centrifugation for the removal of traces of insoluble material, the water extract was dialyzed against distilled water. After centrifugation, the aqueous solution was lyophilized.

Sugar analysis. Polysaccharides were completely hydrolyzed in $2.0 \mathrm{M} \mathrm{CF}_{3} \mathrm{CO}_{2} \mathrm{H}\left(115^{\circ} \mathrm{C}, 1.5 \mathrm{~h}\right)$. The sugars were converted to alditol acetates by reduction, followed by treatment with acetic anhydride in an equal volume of pyridine $\left(100^{\circ} \mathrm{C}, 1 \mathrm{~h}\right)$, and then analyzed by gas-liquid chromatography (GLC) using a GC-2014AF instrument (Shimadzu, Kyoto, Japan) equipped with a flame ionization detector and a $30 \mathrm{~m} \times 0.25 \mathrm{~mm}$ (0.25 mM) DB-225 capillary column (J and W Scientific, CA, USA).

Other chemical analyses. Total carbohydrate concentration was determined by the phenol-sulfuric acid method, using a mixture of D-mannose and D-glucose as a standard. Total protein was determined with the BCA Protein Assay Regent Kit (PIERCE Biotechnology, Rockford, Illinois, USA), using bovine serum albumin as a standard.

Administration schedule for induction of coronary arteritis (Nagi-Miura et al., 2006). We used the $\mathrm{DBA} / 2$ mouse strain for this experiment because it showed the most serious coronary arteritis after treatment with CAWS. Cell wall extracts $(4 \mathrm{mg} /$ mouse) were administered intraperitoneally to each mouse for 5 consecutive days in week 1 . The hearts of the animals were fixed with $10 \%$ neutral formalin and embedded in paraffin blocks. Tissue sections were stained with 
hematoxylin-eosin (HE). Preparation of paraffin blocks and HE staining was done by Biopathology Institute Co., Ltd. (Oita, Japan).

Scoring of rapid anaphylactoid shock. The incidence and the severity of rapid anaphylactoid shock were assessed within $1 \mathrm{~h}$ of i.v. injection $(0.1 \mathrm{~mL} / 10 \mathrm{~g}$ body weight) of cell wall extracts into ICR mice. These values and the subsequent mortality (in the first hour after injection) were recorded. The scoring of shock was as follows: 0 , no symptoms of shock; 1 , staggering; 2 , crawling and prostration; 3 , prostration and weak convulsions; 4 , prostration and strong convulsions.

Nuclear magnetic resonance (NMR) spectroscopy. Exchangeable protons were removed by dissolving cell wall extracts in $\mathrm{D}_{2} \mathrm{O}$, and samples were then lyophilized. This exchange process was repeated three times. All NMR spectra were recorded in $\mathrm{D}_{2} \mathrm{O}$ at $310 \mathrm{~K}$ using a Bruker Avance 500 spectrometer equipped with a TXI $x y z$-three gradient probe for ${ }^{1} \mathrm{H}$ detection. Chemical shifts are reported in ppm relative to acetone- $d_{6}$ as an internal standard $\left(\delta_{\mathrm{H}}=2.189 \mathrm{ppm}, \delta_{\mathrm{C}}=31.45 \mathrm{ppm}\right)$. Data processing was performed using XWinNMR software. The $1 \mathrm{D}-{ }^{1} \mathrm{H}$ experiment was performed using a Bruker standard pulse sequence with $4310 \mathrm{~Hz}$ in $64 \mathrm{~K}$ complex data points. The relaxation delay used was $5 \mathrm{~T}_{1}$ to calculate accurate signal integrations. Prior to Fourier transformation, four times zero filling was used, and noise was reduced using the Trafication function. 2D sensitivity improvement ${ }^{1} \mathrm{H},{ }^{13} \mathrm{C}$-heteronuclear single quantum coherence (HSQC) without decoupling during acquisition was conducted to measure ${ }^{1} J_{\mathrm{H} 1, \mathrm{Cl}}$ with
512 increments of 2048 data points with 32 scans per $t_{1}$ increment using the Bruker standard pulse sequence. The spectral width was $3501 \mathrm{~Hz}$ for $t_{2}$ and $12500 \mathrm{~Hz}$ for $t_{1}$. 2D-total correlation spectroscopy (TOCSY) was conducted with a mixing time for TOCSY spinlock of 30 to $180 \mathrm{~ms}$ using the pulse sequence of Griesinger et al. to suppress ROE signals (Griesinger et al., 1988). The spectral width was $2200 \mathrm{~Hz}$ in each dimension and 512 increments of 4096 data points with 16 scans per $t 1$ increment were recorded. All 2D experiments were zero-filled to $2 \mathrm{k}$ and $2 \mathrm{k}$ in both dimensions prior to Fourier transformation. A cosine-bell window function was applied in both dimensions.

\section{Results}

Chemical composition of cell wall extracts from C. metapsilosis. The chemical composition of cell wall extracts from C. metapsilosis NBRC 0640 cultured at various temperatures is summarized in Table I. All extracts were mainly composed of carbohydrates (64.4$78.5 \%)$ and proteins (18.9\%). The monosaccharide content of cell wall extracts was determined by GLC analysis. Only mannose and glucose were detected. These analyses clearly indicate that the cell wall extracts contained the mannoprotein-glucan complex.

Coronary arteritis induced by $C$. metapsilosis cell wall extracts. We first examined the coronary arteritis induction activity of C. metapsilosis cell wall extracts. Fig. 1 shows HE staining of the aorta in cell wall extract

Table I

Chemical composition of cell wall extracts from Candida metapsilosis

\begin{tabular}{|c|c|c|c|c|c|c|}
\hline Culture medium & $\begin{array}{c}\text { Culture } \\
\text { temperature }\left({ }^{\circ} \mathrm{C}\right)\end{array}$ & $\begin{array}{c}\text { Yield } \\
(\%)\end{array}$ & $\begin{array}{c}\text { Total } \\
\text { carbohydrate }(\%)\end{array}$ & $\begin{array}{c}\text { Total protein } \\
(\%)\end{array}$ & $\begin{array}{c}\text { Elemental analysis } \\
(\mathrm{C}: \mathrm{H}: \mathrm{N}))\end{array}$ & $\begin{array}{c}\text { Sugar composition } \\
(\mathrm{Man}: \mathrm{Glc})\end{array}$ \\
\hline \multirow{2}{*}{ C-limiting medium } & 27 & 26.4 & 64.4 & 18.9 & $41.59: 7.03: 3.95$ & $0.66: 1.0$ \\
\cline { 2 - 7 } & 37 & 20.4 & 78.5 & 28.9 & $42.57: 7.05: 5.53$ & $1.2: 1.0$ \\
\hline
\end{tabular}

Table II

Ability of cell wall extracts to induce rapid anaphylactoid shock in ICR mice

\begin{tabular}{|c|c|c|c|c|c|}
\hline \multirow{3}{*}{$\begin{array}{c}\text { Culture } \\
\text { medium }\end{array}$} & \multirow{2}{*}{$\begin{array}{c}\text { Culture } \\
\text { temperature }\left({ }^{\circ} \mathrm{C}\right)\end{array}$} & \multirow{2}{*}{$\begin{array}{c}\text { Dose } \\
(\mathrm{mg} / \mathrm{kg})\end{array}$} & \multicolumn{3}{|c|}{ Anaphylactoid shock } \\
\cline { 3 - 6 } & \multirow{3}{*}{27} & 4 & $0 / 12$ & 0 & $0 / 12$ \\
\hline \multirow{3}{*}{ C-limiting } & 8 & $12 / 12$ & $1-4$ & $10 / 12$ \\
\cline { 3 - 6 } & & 16 & $12 / 12$ & 4 & $12 / 12$ \\
\cline { 3 - 6 } & \multirow{3}{*}{37} & 4 & $0 / 12$ & 0 & $0 / 12$ \\
\cline { 3 - 6 } & & 8 & $12 / 12$ & 4 & $11 / 12$ \\
\cline { 3 - 6 } & & 16 & $12 / 12$ & $3-4$ & $12 / 12$ \\
\hline
\end{tabular}

Indicated dose $(\mathrm{mg} / \mathrm{kg})$ was i.v. administered to mice $(\mathrm{n}=12)$. Mortality was monitored within $1 \mathrm{~h}$. ???/????, number of mice, dead/total. a) The scoring of the shock was as follows: 0 , no symptoms of shock; 1, staggering; 2, crawling and prostration; 3 , prostration and weak convulsions; 4 , prostration and strong convulsions. 


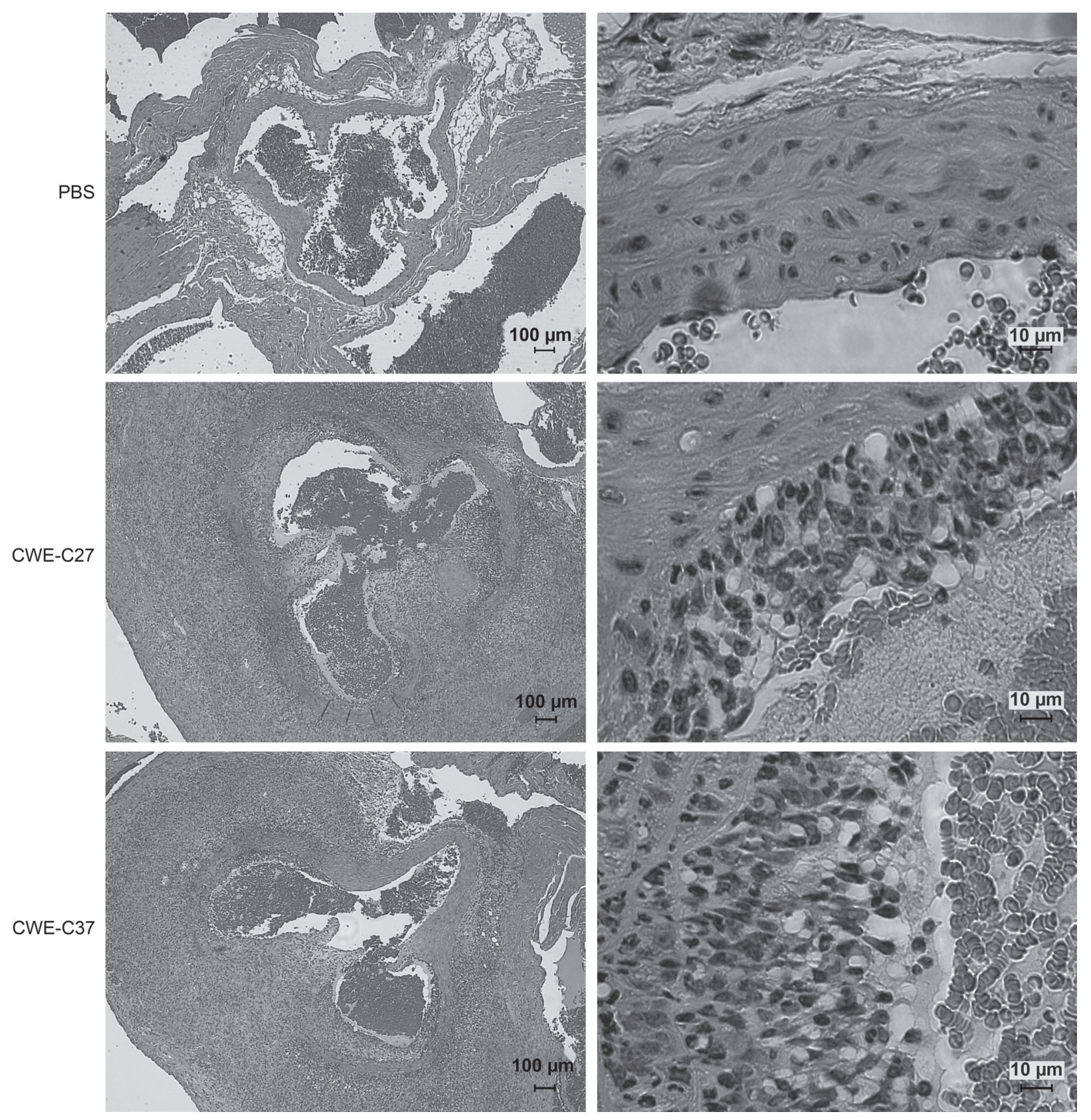

Fig. 1. Histological examination of a hot water extract from Candida metapsilosis-induced coronary arteritis in mice.

CWE-C27 and CWE-C37 (4 mg/mouse) were administered i.p. to DBA/2 mice for 5 consecutive days in the first week. Five weeks later, the hearts of DBA/2 mice were fixed in buffered formalin solution, embedded in paraffin, thin-sectioned, stained with hematoxylin-eosin, and then observed microscopically. Scale bars are depicted in the figure.

(CWE)-administered DBA/2 mice. As revealed by histological examination, intraperitoneal injection of CWE induced severe coronary arteritis in DBA/2 mice. This result implies that environmental conditions around cells might not alter C. metapsilosis cell wall mannan structure, unlike that which occurs in C. albicans.

Rapid anaphylactoid shock induced by C. metapsilosis cell wall extracts derived from various culture conditions. Next, we examined another typical biological effect exhibited by Candida cell wall mannan and found that all CWE administration resulted in acute anaphylactoid shock in ICR mice (Table II). The trend of these pathogenic effects is mirrored in the vasculitisinducible activity.

NMR analyses of cell wall extracts from C. metapsilosis cultured under various conditions. We next analyzed the structure of cell wall mannan using NMR spectroscopy, because we had previously found that the mannan structure is vital in determining its biological activities. Figure 2 shows $1 D^{-}{ }^{1} \mathrm{H}$ NMR spectra of cell wall extracts. Each spectrum contains many signals in the anomeric region (4.5-5.5 ppm). However, it is apparent that the carbohydrates in cell wall extracts were not altered even when culture temperatures were 


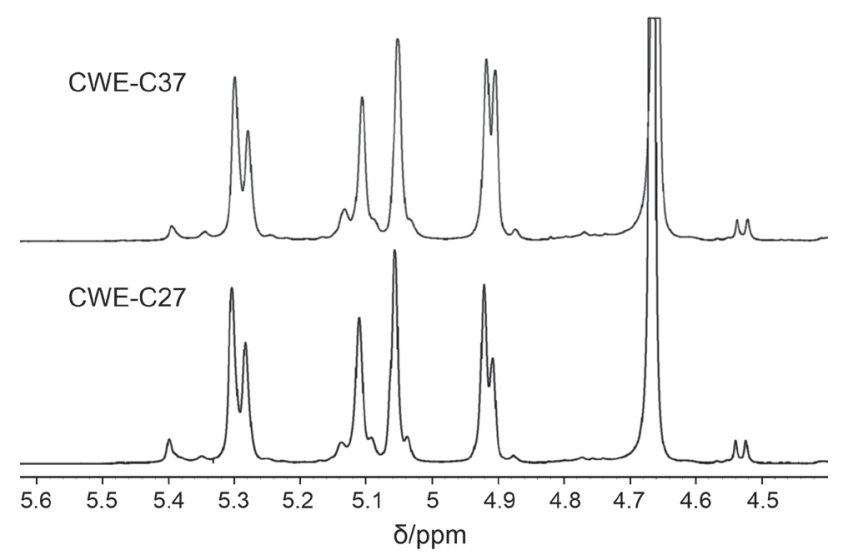

Fig. 2. 1D- ${ }^{1} \mathrm{H}$ NMR spectrum of a hot water extract from Candida metapsilosis.

$1 \mathrm{D}-{ }^{1} \mathrm{H}$ NMR spectra of hot water extracts of C. metapsilosis derived from various culture conditions. All spectra were recorded in $\mathrm{D}_{2} \mathrm{O}$ at $310 \mathrm{~K}$ using a Bruker Avance 500 spectrometer equipped with a TXI $x y z$-three gradient probe for ${ }^{1} \mathrm{H}$ detection. Chemical shifts are reported in ppm relative to acetone- $d_{6}$ as the internal standard $\left(\delta_{\mathrm{H}}=2.189 \mathrm{ppm}\right)$.

changed. We confirmed this using ${ }^{1} \mathrm{H},{ }^{13} \mathrm{C}-\mathrm{HSQC}$ spectra. Figure 3 shows overlaid HSQC (black) spectra of CWE-C27, and (green) CWE-C37. The overlaid HSQC spectra show 10 signals of mannose residues in their anomeric region $\left(\delta_{\mathrm{H}} 4.5-5.5 \mathrm{ppm}, \delta_{\mathrm{C}} 100-105 \mathrm{ppm}\right)$ that were arbitrarily labeled nos. $1-10$ as described in Table III. Since we could not completely assign all signals, we examined the anomeric conformation of their carbohydrate residues because numerous studies have reported that the anomeric conformation of mannose residues is crucial for their pathogenicity and antigenicity. From the observed ${ }^{1} J_{\mathrm{H} 1, \mathrm{Cl}}$ obtained from ${ }^{1} \mathrm{H},{ }^{13} \mathrm{C}$ HSQC spectra without decoupling during acquisition, all mannose residues were assigned to a-mannose. We next examined samples using 2D-TOCSY spectra to determine the linkage types of each residue by the method of Shibata et al. (Shibata et al., 2007). No quality differences were detected by the NMR experiments.

\section{Discussion}

In this study, we showed the following: (i) injecting cell wall carbohydrate extracts from the fungus C. metapsilosis into mice induced severe coronary arteritis similar to KS as well as acute anaphylactoid shock;

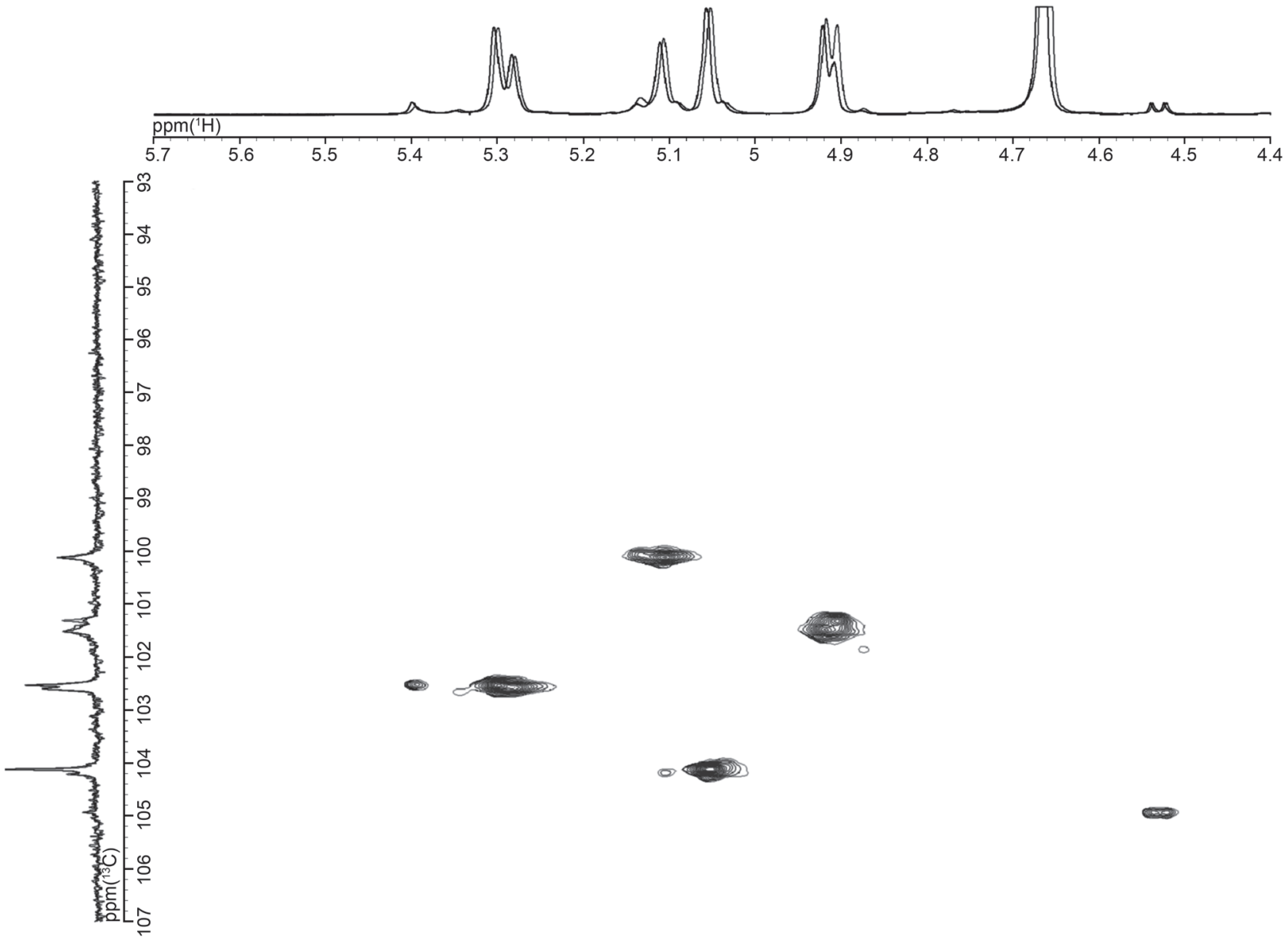

Fig. 3. Overlaid ${ }^{1} \mathrm{H},{ }^{13} \mathrm{C}-\mathrm{HSQC}$ spectrum of hot water extracts from Candida metapsilosis

The overlaid ${ }^{1} \mathrm{H},{ }^{13} \mathrm{C}-\mathrm{HSQC}$ spectra from (black) CWE-C27 and (green) CWE-C37 were recorded in $\mathrm{D}_{2} \mathrm{O}$ at $310 \mathrm{~K}$ using a Bruker Avance 500 spectrometer equipped with a TXI $x y z$-three gradient probe for ${ }^{1} \mathrm{H}$ detection. Chemical shifts are reported in ppm relative to acetone- $d_{6}$ as the internal standard $\left(\delta_{\mathrm{H}}=2.189 \mathrm{ppm} ; \delta_{\mathrm{C}}=31.45 \mathrm{ppm}\right)$. 
Table III

Anomeric conformation analyses of hot water cell wall extracts of Candida metapsilosis cultured in various culture conditions

\begin{tabular}{|r|c|c|c|l|c|c|l|}
\hline & & & & \multirow{2}{*}{} & \multicolumn{2}{|c|}{ Contain } & \multirow{2}{*}{ Residue } \\
\cline { 6 - 7 } & & & & & & \\
\end{tabular}

(ii) the pathogenic effects were not altered by changing the environmental conditions such as growth temperature; and (iii) cell wall extracts from C. metapsilosis, which induced severe vasculitis and shock, contained $\alpha$-mannan but not $\beta$-mannan. These findings strongly indicate that cell wall mannan from both C.albicans and C. metapsilosis might contribute to Candida pathogenicity, causing coronary arteritis and acute shock. These effects are seen only in the absence of the significant $\beta$-mannan.

The cell wall extracts used in this study were mainly composed of carbohydrates (mannose and glucose) and protein (Table I). The extracts dramatically induced coronary arteritis (Figure 1) and acute anaphylactoid shock (Table II) in mice, similar to the effects of extracts from C. albicans. We have previously reported that Candida a-mannan might be responsible for these pathogenic activities, and that additional $\beta$-mannan expression within the mannan moiety neutralizes the effect (Tada et al., 2008; Shinohara et al., 2006). Other studies showed that 1,2- $\beta$-linked mannans, which are only expressed by pathogenic yeasts such as $C$. albicans, are vital for either pathogenic or virulent processes such as adhesion to host cells (Dalle et al., 2003) and cytokine production from various cells (Fradin et al., 2000). This specific glycan can bind to galectin-3, which is the receptor for 1,2- $\beta$-linked mannan, but not to typical mannan receptors such as the macrophage mannose receptor or mannose-binding lectin, and it may contribute to some biological effects of mannan (Jouault et al., 2006; Kohatsu et al., 2006). However, a-mannan still seems to play central roles in the antigenicity and pathogenicity of fungal cell wall mannans, especially those from Candida spp. For instance, Saijo et al., reported that C-type lectin, dectin-2, is a crucial receptor for the a-mannan from C. albicans and plays an important role in host defense against this fungus. Specifically, cytokine production and signal transduction stimu- lated by a-mannan from C. albicans were completely abolished in dectin- $2^{-/-}$mice as compared to wild-type (Saijo et al., 2010). We, therefore, used NMR spectroscopy to analyze the structure of cell wall mannans from C. metapsilosis, because altering culture conditions did not affect the pathogenic effects of C. metapsilosis cell wall extracts, implying that the environmental shift did not change its mannan structure. NMR analysis confirmed that all C. metapsilosis cell wall mannans contain only a-mannosyl residues (Figures 2 and 3, Table III). C-type lectin for mannan, such as mannose-binding lectin, binds to the $\alpha$-mannan via the equatorial position of 3- and 4-hydroxyl groups (Weis et al., 1992). However, $\beta$-mannan cannot bind to the mannose type lectin, maybe owing to its specific helical conformation in solution (Nitz et al., 2002), leading to masking the $\alpha$-mannose residues. These results strongly indicate that $\alpha$-mannan but not $\beta$-mannan contributes to the pathogenic effects of cell wall extracts from C. metapsilosis.

Further studies are needed to clarify the mechanism(s) underlying these pathogenic effects. However, our group recently revealed the following: (i) in mice, CCR2 knock out, but not CCR5, protects against CAWS-induced coronary vasculitis; (ii) both $\mathrm{T}$ cells and B cells, which are directly modulated by CCR2, play pivotal roles in the induction of coronary vasculitis by CAWS; (iii) CAWS promotes mobilization of CCR2-dependent inflammatory monocytes (Martinez et al., 2012); importantly (iv) the suppression of CAWSinduced neutrophil infiltration into the coronary arteries and aortic root using a synthetic retinoid, Am80, attenuates vasculitis, indicating that neutrophils play a contributory role in the CAWS-induced vasculitis (Miyabe et al., 2013); (v) CAWS markedly enhances the expression of complement system genes, such as C3, C4, complement factor b, complement factor h, and ficolin-A, in DBA/2 mice as compared with that in the $\mathrm{C} 57 \mathrm{BL} / 6$ mice (the strain which shows only mild 
symptoms) (Shinohara et al. 2006; Miura et al., 2013); (vI) CAWS also dramatically induces the expression of the interferon- $\gamma$ (IFN- $\gamma$ )-related gene only in the DBA/2 mice (Miura et al., 2013). These facts clearly indicate that polysaccharide fractions isolated from Candida exert their pathogenic effects in concert with various types of cells and factors, including complements, cytokines, and chemokines. However, we do not yet know why CAWS induces IFN- $\gamma$ and complement system gene expression to such an extent in the $\mathrm{DBA} / 2$ mice, because these mice show the most severe CAWS-induced vasculitis when compared with other complement-deficient mice, such as $\mathrm{AKR} / \mathrm{N}$ and $\mathrm{A} / \mathrm{J}$ strains (unpublished results).

The present study strongly suggests that C. metapsilosis, a less pathogenic fungus than C.albicans, could also cause coronary arteritis such as that observed during KS and fungal-induced sepsis. Since cell wall extracts contain only a-mannosyl residues (no $\beta$-mannan), the results of this study support our previous results. However, further studies are needed because the precise mechanism(s) behind these pathogenic activities is not understood. Nevertheless, these findings suggest the possibility of a novel strategy for drug therapy: regulation of the biosynthesis of Candida mannan. This could be a candidate for the therapy of coronary arteritis and acute anaphylactoid shock.

\section{Acknowledgments}

This study was supported by the Program for Promotion of Basic and Applied Researches for Innovations in Bio-oriented Industry (BRAIN).

\section{Literature}

Akiyama T. and K. Yashiro. 1993. Probable role of Streptococcus pyogenes in Kawasaki disease. Eur. J. Pediatr. 152: 82-92. Arana D.M., D. Prieto, E. Roman, C. Nombela, R. Alonso-Monge and J. Pla. 2009. The role of the cell wall in fungal pathogenesis. Microb. Biotechnol. 2: 308-320.

Bille J., O. Marchetti and T. Calandra. 2005. Changing face of healthcare associated fungal infections. Curr. Opin. Infect. Dis. 18: 314-319. Bourgeois C., O. Majer, I.E. Frohner, L. Tierney and K. Kuchler. 2010. Fungal attacks on mammalian hosts: pathogen elimination requires sensing and tasting. Curr. Opin. Microbiol. 13: 401-408.

Bowman S.M. and S.J. Free. 2006. The structure and synthesis of the fungal cell wall. Bioessays. 28: 799-808.

Burns J.C. 2009. Kawasaki Disease update. Indian. J. Pediatr. 76: 71-76.

Dalle F., T. Jouault, P.A. Trinel, J. Esnault, J.M. Mallet, P. d'Athis, D. Poulain and A. Bonnin. 2003. Beta-1,2- and alpha-1,2-linked oligomannosides mediate adherence of Candida albicans blastospores to human enterocytes in vitro. Infect. Immun. 71: 7061-7068. Esper F., E.D. Shapiro, C. Weibel, D. Ferguson, M.L. Landry and J.S. Kahn. 2005. Association between a novel human coronavirus and Kawasaki disease. J. Infect. Dis. 191: 499-502.

Fradin C., D. Poulain and T. Jouault. 2000. beta-1,2-linked oligomannosides from Candida albicans bind to a 32-kilodalton mac- rophage membrane protein homologous to the mammalian lectin galectin-3. Infect. Immun. 68: 4391-4398.

Griesinger C., G. Otting, K. Wuthrich and R. Ernst. 1988. Clean TOCSY for proton spin system identification in macromolecules. J. Am. Chem. Soc. 110: 7870-7872.

Jarvis W.R. 1995. Epidemiology of nosocomial fungal infections, with emphasis on Candida species. Clin. Infec.t Dis. 20: 1526-1530. Jouault T., M. El Abed-El Behi, M. Martinez-Esparza, L. Breuilh, P.A. Trinel, M. Chamaillard, F. Trottein and D. Poulain. 2006. Specific recognition of Candida albicans by macrophages requires galectin-3 to discriminate Saccharomyces cerevisiae and needs association with TLR2 for signaling. J. Immunol. 177: 4679-4687.

Klis F.M., P. de Groot and K. Hellingwerf. 2001. Molecular organization of the cell wall of Candida albicans. Med. Mycol. 39: Suppl. 1, $1-8$.

Kobayashi H., S. Takahashi, N. Shibata, M. Miyauchi, M. Ishida, J. Sato, K. Maeda and S. Suzuki. 1994. Structural modification of cell wall mannans of Candida albicans serotype A strains grown in yeast extract-Sabouraud liquid medium under acidic conditions. Infect. Immun. 62: 968-973.

Kohatsu L., D.K. Hsu, A.G. Jegalian, F.T. Liu and L.G. Baum. 2006. Galectin-3 induces death of Candida species expressing specific beta-1,2-linked mannans. J. Immunol. 177: 4718-4726.

Koyama T., M. Makita, N. Shibata and Y. Okawa. 2009. Influence of oxidative and osmotic stresses on the structure of the cell wall mannan of Candida albicans serotype A. Carbohydr. Res. 344: 2195-2200. Krcmery Y. and A.J. Barnes. 2002. Non-albicans Candida spp. causing fungaemia: pathogenicity and antifungal resistance. J. Hosp. Infect. 50: 243-260.

Levy I., I. Shalit, E. Birk, L. Sirota, S. Ashkenazi, B. German and N. Linder. 2006. Candida endocarditis in neonates: report of five cases and review of the literature. Mycoses 49: 43-48.

Martinez H.G., M.P. Quinones, F. Jimenez, C. Estrada, K.M. Clark, K. Suzuki, N. Miura, N. Ohno, S.K. Ahuja and S.S. Ahuja. 2012. Important role of CCR2 in a murine model of coronary vasculitis. BMC Immunology 13: 56.

Miura N.N., M. Komai, Y. Adachi, N. Osada, Y. Kameoka, K. Suzuki and N. Ohno. 2009. IL-10 is a negative regulatory factor of CAWS-vasculitis in CBA/J mice as assessed by comparison with Bruton's tyrosine kinase-deficient CBA/N mice. J. Immunol. 183: 3417-3424.

Miura N.N., D. Okuzaki, K. Torigata, A.M. Sakurai, A. Ito, N. Ohno and H. Nojima H. 2013. CAWS administration increases the expression of interferon $\gamma$ and complement factors that lead to severe vasculitis in DBA/2 mice. BMC Immunol. 14: 44.

Miyabe C., Y. Miyabe, N.N. Miura, K. Takahashi, Y. Terashima, E. Toda, F. Honda, T. Morio, N. Yamagata, N. Ohno, K. Shudo, J. Suzuki, M. Isobe, K. Matsushima, R. Tsuboi, N. Miyasaka and T. Nanki. 2013. Am80, a retinoic acid receptor agonist, ameliorates murine vasculitis through the suppression of neutrophil migration and activation. Arthritis and rheumatism 65: 503-512.

Nagi-Miura N., T. Harada, H. Shinohara, K. Kurihara, Y. Adachi, A. Ishida-Okawara, T. Oharaseki, K. Takahashi, S. Naoe, K. Suzuki and N. Ohno. 2006. Lethal and severe coronary arteritis in DBA/2 mice induced by fungal pathogen, CAWS, Candida albicans water-soluble fraction. Atherosclerosis 186: 310-320.

Nather K. and C.A. Munro. 2008. Generating cell surface diversity in Candida albicans and other fungal pathogens. FEMS Microbiol Lett. 285: 137-145.

Nitz M., C.C. Ling, A. Otter, J.E. Cutler and D.R. Bundle. 2002. The unique solution structure and immunochemistry of the Candida albicans beta -1,2-mannopyranan cell wall antigens. J. Biol. Chem. 277: 3440-3446.

Ohno N. 2008. A murine model of vasculitis induced by fungal polysaccharide. Cardiovasc Hematol Agents Med Chem. 6: 44-52. 
Okawa Y., K. Goto, S. Nemoto, M. Akashi, C. Sugawara, M. Hanzawa, M. Kawamata, T. Takahata, N. Shibata, H. Kobayashi and S. Suzuki. 1996. Antigenicity of cell wall mannans of Candida albicans NIH B-792 (serotype B) strain cells cultured at high temperature in yeast extract-containing sabouraud liquid medium. Clin. Diagn. Lab. Immunol. 3: 331-336.

Poulain D. and T. Jouault. 2004. Candida albicans cell wall glycans, host receptors and responses: elements for a decisive crosstalk. Curr. Opin. Microbiol. 7: 342-349.

Ruiz-Herrera J., M.V. Elorza, E. Valentin and R. Sentandreu. 2006. Molecular organization of the cell wall of Candida albicans and its relation to pathogenicity. FEMS Yeast. Res. 6: 14-29.

Saijo S., S. Ikeda, K. Yamabe, S. Kakuta, H. Ishigame, A. Akitsu, N. Fujikado, T. Kusaka, S. Kubo, S.H. Chung, R. Komatsu, N. Miura, Y. Adachi, N. Ohno, K. Shibuya, N. Yamamoto, K. Kawakami, S. Yamasaki, T. Saito, S. Akira and Y. Iwakura. 2010. Dectin-2 recognition of alpha-mannans and induction of Th17 cell differentiation is essential for host defense against Candida albicans. Immunity 32: 681-691.

Shepherd M.G. and P.A. Sullivan. 1976. The production and growth characteristics of yeast and mycelial forms of Candida albicans in continuous culture. J. Gen. Microbiol. 93: 361-370.

Shibata N., K. Ikuta, T. Imai, Y. Satoh, R. Satoh, A. Suzuki, C. Kojima, H. Kobayashi, K. Hisamichi and S. Suzuki. 1995. Existence of branched side chains in the cell wall mannan of pathogenic yeast, Candida albicans. Structure-antigenicity relationship between the cell wall mannans of Candida albicans and Candida parapsilosis. J. Biol. Chem. 270: 1113-1122.

Shibata N., A. Suzuki, H. Kobayashi and Y. Okawa. 2007. Chemical structure of the cell-wall mannan of Candida albicans serotype A and its difference in yeast and hyphal forms. Biochem. J. 404: 365-372. Shinohara H., N. Nagi-Miura, K. Ishibashi, Y. Adachi, A. IshidaOkawara, T. Oharaseki, K. Takahashi, S. Naoe, K. Suzuki and N. Ohno. 2006. Beta-mannosyl linkages negatively regulate anaphylaxis and vasculitis in mice, induced by CAWS, fungal PAMPS composed of mannoprotein-beta-glucan complex secreted by Candida albicans. Biol. Pharm. Bull. 29: 1854-1861.

Tada R., N. Nagi-Miura, Y. Adachi and N. Ohno. 2006. Candida albicans derived fungal PAMPS, CAWS, water soluble mannoprotein-beta-glucan complex shows similar immunotoxicological activity with bacterial endotoxin from Escherichia coli O9. Biol Pharm Bull. 29: 240-246.

Tada R., N. Nagi-Miura, Y. Adachi and N. Ohno. 2008. The influence of culture conditions on vasculitis and anaphylactoid shock induced by fungal pathogen Candida albicans cell wall extract in mice. Microb. Pathog. 44: 379-388.

Tada R., Y. Takano, H. Murakami, K. Ishibashi, N. Nagi-Miura, Y. Adachi and N. Ohno. 2011. Vasculitis and anaphylactoid shock in mice induced by the polysaccharide fraction secreted into culture supernatants by the fungus Candida metapsilosis. Microbiol. Immunol. 55: 357-365.

Tay S.T., S.L. Na and J. Chong. 2009. Molecular differentiation and antifungal susceptibilities of Candida parapsilosis isolated from patients with bloodstream infections. J. Med. Microbiol. 58: 185-191. Wang C.L., Y.T. Wu, C.A. Liu, H.C. Kuo and K.D Yang. 2005. Kawasaki disease: infection, immunity and genetics. Pediatr. Infect. Dis. J. 24: 998-1004.

Weis W.I., K. Drickamer and W.A. Hendrickson. 1992. Structure of a C-type mannose-binding protein complexed with an oligosaccharide. Nature 360: 127-134. 